\title{
Design of 2D Self-Supported Hybrid CuSe@PANI CoreShell Nanosheet Arrays for High-Performance Flexible \\ Microsupercapacitors
}

Jing-Chang Lia ${ }^{a}$, Jiangfeng Gonga*, Ziyuan Yang a , Yazhou Tiana ${ }^{\mathrm{a}}$, Xincheng Zhang ${ }^{\mathrm{a}}$, Qianjin Wang ${ }^{\mathrm{b}}$, Xuhao Hong ${ }^{\mathrm{b}}$

${ }^{a}$ College of Science, Hohai University, Nanjing 210098, P. R. China.

${ }^{b}$ Nanjing National Laboratory of Solid State Microstructures, Nanjing University, Nanjing 210093, People's Republic of China

* To whom correspondence should be addressed. E-mail: jfgong@hhu.edu.cn. 


\section{Electronic Supplementary Information}

\section{The growth mechanism of CuSe nanosheet arrays.}

The mechanism of growing $\mathrm{CuSe}$ on $\mathrm{Au} / \mathrm{PET}$ substrate has been reported in our previous work ${ }^{1}$. In brief, the co-electrodeposition of $\mathrm{Cu}$ and $\mathrm{Se}$ on $\mathrm{Au} / \mathrm{PET}$ can obtain in the potential ranging from $-0.2 \mathrm{~V}$ to $+0.1 \mathrm{~V}^{1-4}$. When the applied potential is around $-0.1 \mathrm{~V}$, the ratio of $\mathrm{Cu}$ and $\mathrm{Se}$ is close to $1: 1$. Moreover, the CuSe obtained at this condition exhibits vertically- aligned nanosheet structure with a large number of open channels. This porous structure is used as skeletons for PANI in our work. The total reaction can be written as ${ }^{2-4}$ :

$$
\mathrm{HSO}_{3}^{-}+5 \mathrm{H}^{+}+\mathrm{Cu}^{2+}+6 \mathrm{e}^{-}=\mathrm{CuSe}+3 \mathrm{H}_{2} \mathrm{O}
$$

a

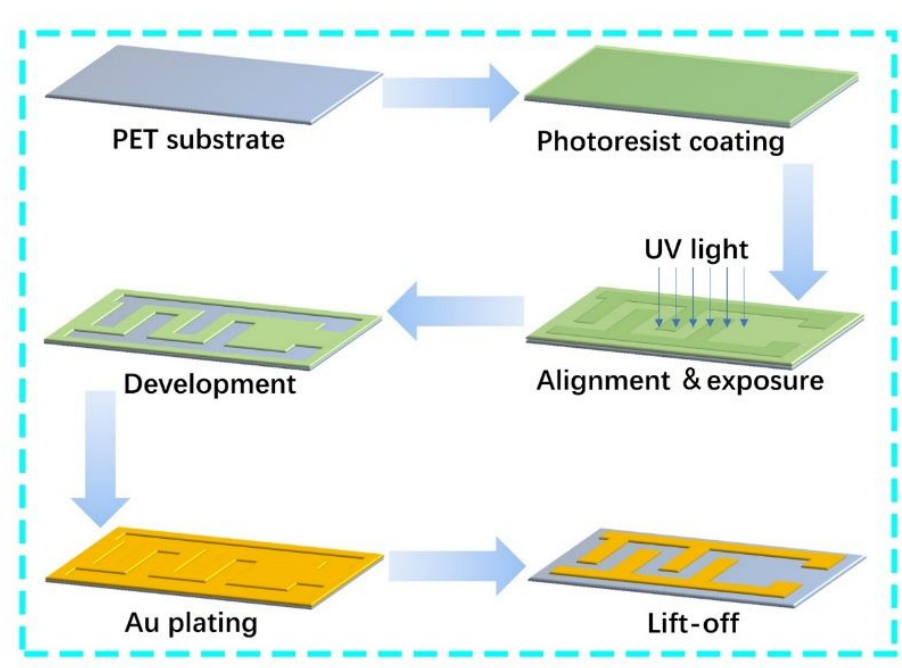

b

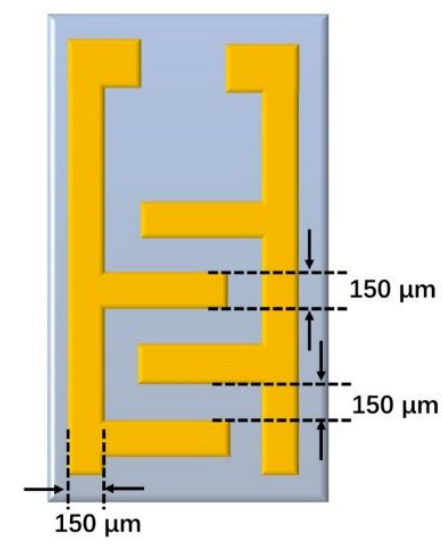

Fig. S1. (a) Schematic illustration of fabrication process and (b) Dimensions of the Aucoated interdigital micro-electrodes. 
Electronic Supplementary Information
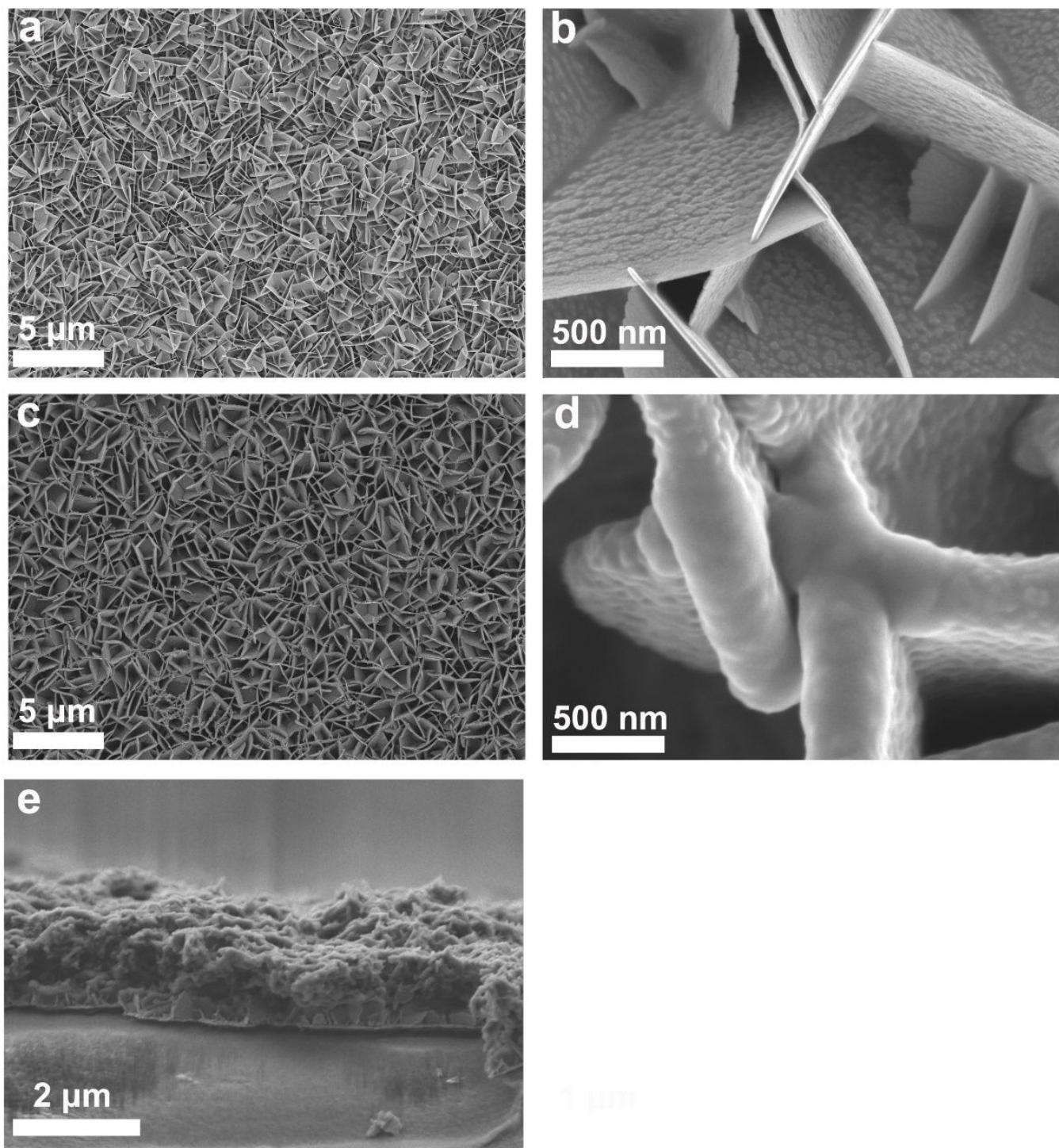

Fig. S2. (a) Low and (b) high magnification SEM images of CuSe nanosheet skeletons.

(c) Low and (d) high magnification SEM images of CuSe@PANI nanosheet arrays. (e)

Cross-sectional SEM image of CuSe@PANI. 
Electronic Supplementary Information

\begin{tabular}{c|ccc}
\hline \multicolumn{1}{c}{ Vibration models } & Position & Reference \\
\hline CuSe & Se-Se & $241.70 \mathrm{~cm}^{-1}, 261.35 \mathrm{~cm}^{-1}$ & 5,6 \\
\hline \multirow{5}{*}{ PANI } & Ring deformation (out-plane) & $418.04 \mathrm{~cm}^{-1}, 527.07 \mathrm{~cm}^{-1}$ & 7 \\
& Ring deformation (in-plane) & $576.67 \mathrm{~cm}^{-1}$ & 7,8 \\
& Substituted benzene rings & $778.24 \mathrm{~cm}^{-1}$ & 9 \\
& C-H bending (out-plane) & $812.03 \mathrm{~cm}^{-1}$ & 10 \\
& $\mathrm{C}-\mathrm{H}$ bending (in-plane) & $1166.34 \mathrm{~cm}^{-1}$ & 10 \\
& $\mathrm{C}-\mathrm{N}$ stretching & $1218.01 \mathrm{~cm}^{-1}$ & $8,11,12$ \\
& $\mathrm{C} \sim \mathrm{N}^{+\cdot}$ stretching & $1332.4 \mathrm{~cm}^{-1}$ & $8,11,12$ \\
& $\mathrm{C}-\mathrm{C}$ stretching & $1415.35 \mathrm{~cm}^{-1}, 1615.36 \mathrm{~cm}^{-1}$ & 10,13 \\
& $\mathrm{C}=\mathrm{N}$ stretching & $1477.37 \mathrm{~cm}^{-1}$ & 7,14 \\
& $\mathrm{C}=\mathrm{C}$ stretching & $1595.15 \mathrm{~cm}^{-1}$ & 7,14 \\
\hline
\end{tabular}

Table S1. The assignments of Raman peaks for CuSe and PANI.

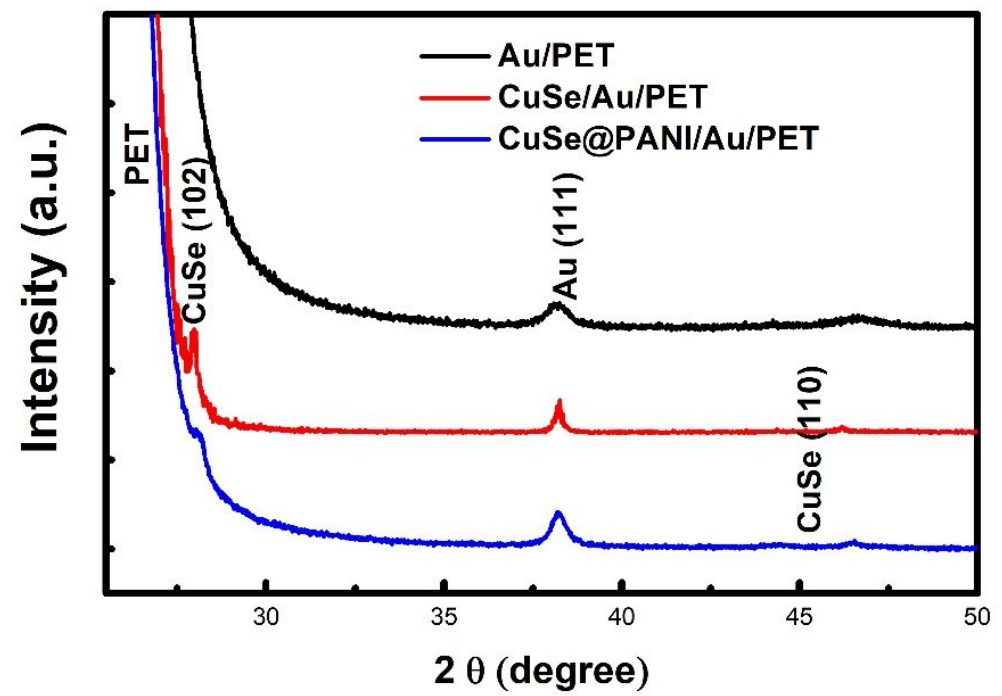

Fig. S3. XRD patterns of Au/PET, CuSe/Au/PET and CuSe@PANI Au/PET. 

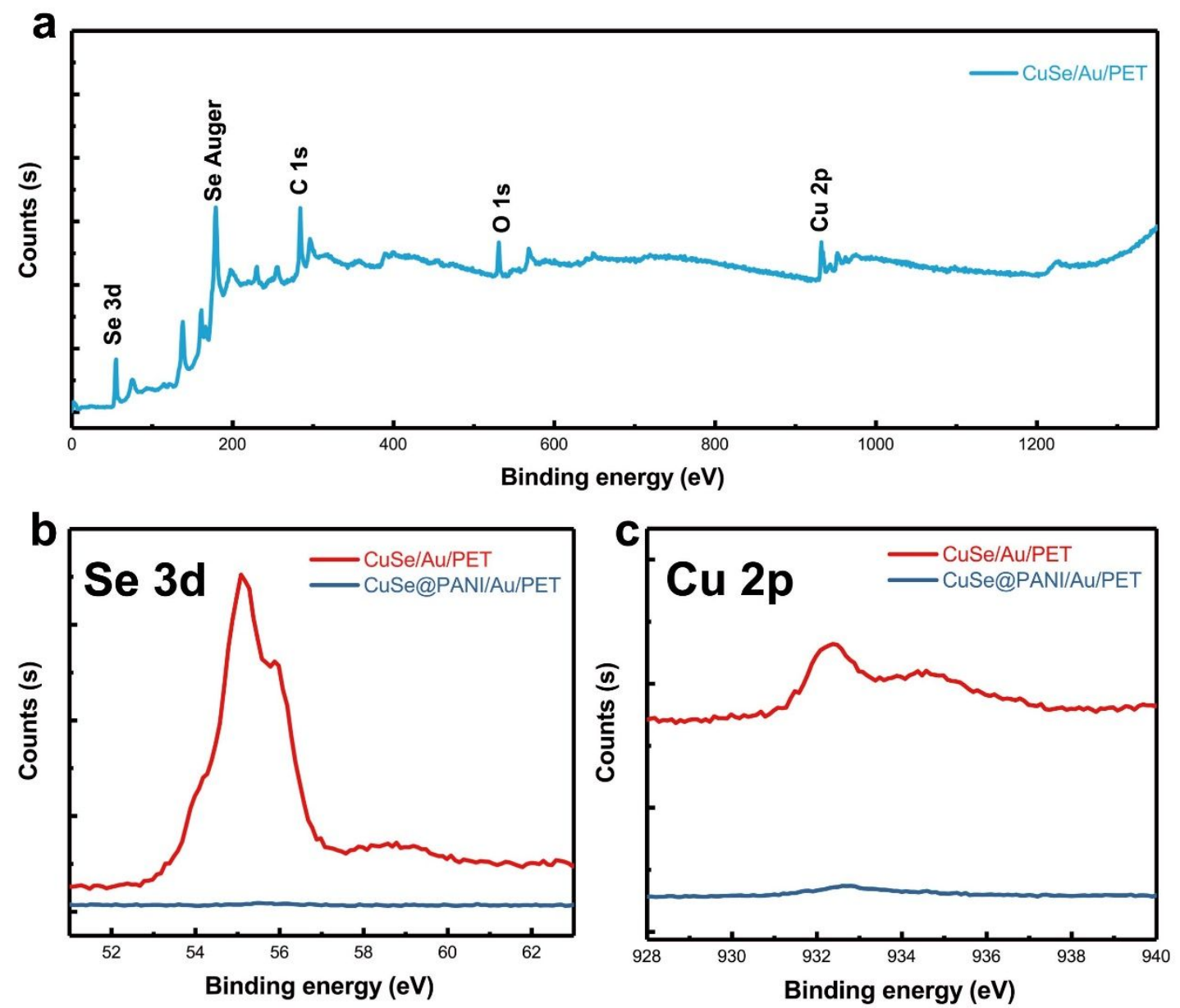

Fig. S4. (a) The survey XPS spectra of pure CuSe nanosheets. The core level XPS spectra of (b) Se 3d, and (c) Cu 2p. 


\section{Electronic Supplementary Information}
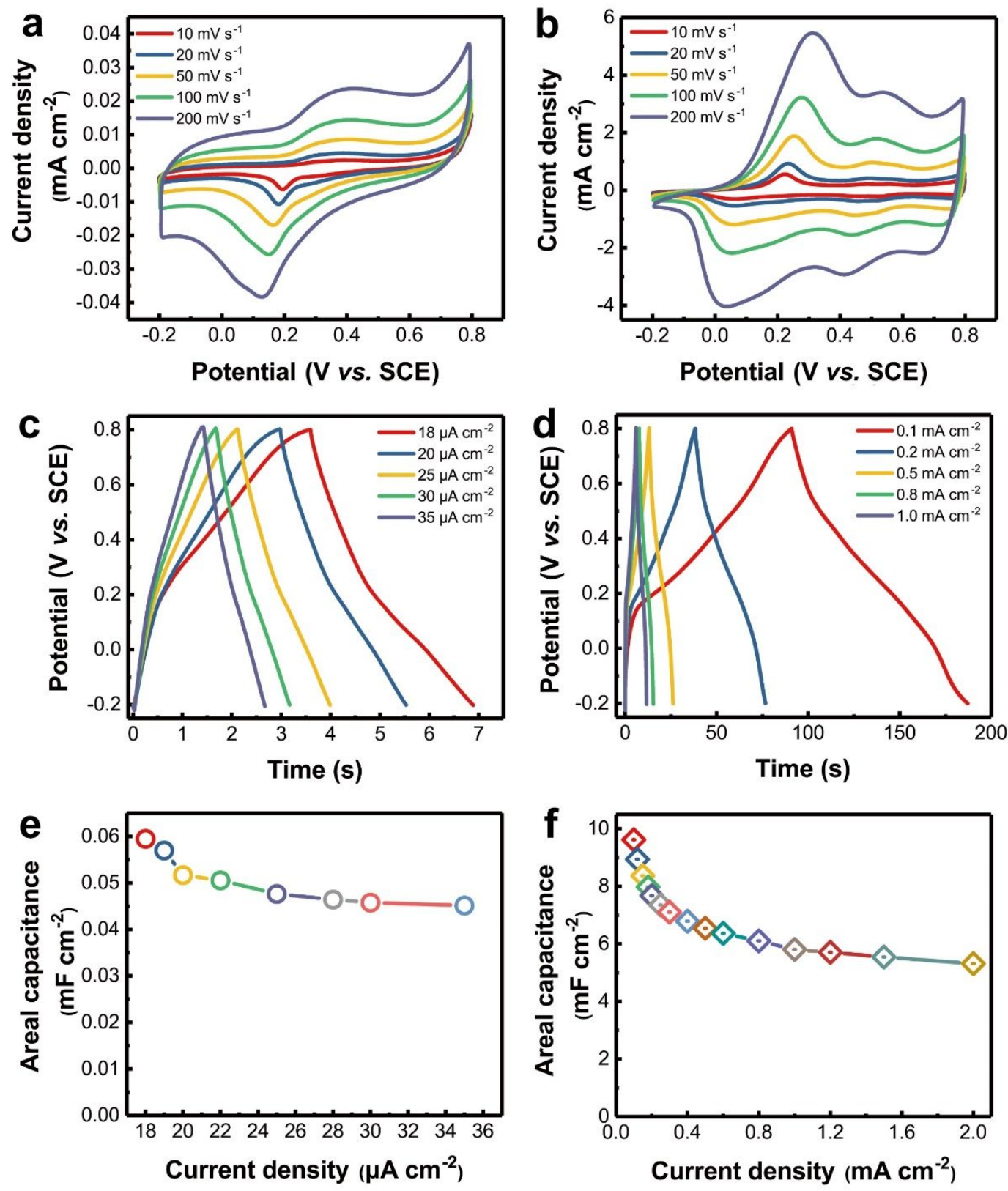

Fig. S5. Electrochemical performance of CuSe, PANI in $1 \mathrm{M} \mathrm{H}_{2} \mathrm{SO}_{4}$. a) $\mathrm{CV}$ curves of CuSe, b) CV curves of PANI, c) GCD curves of CuSe, d) GCD curves of PANI, e) areal capacitances of $\mathrm{CuSe}, \mathrm{f}$ ) areal capacitances of PANI. 


\section{Electronic Supplementary Information}
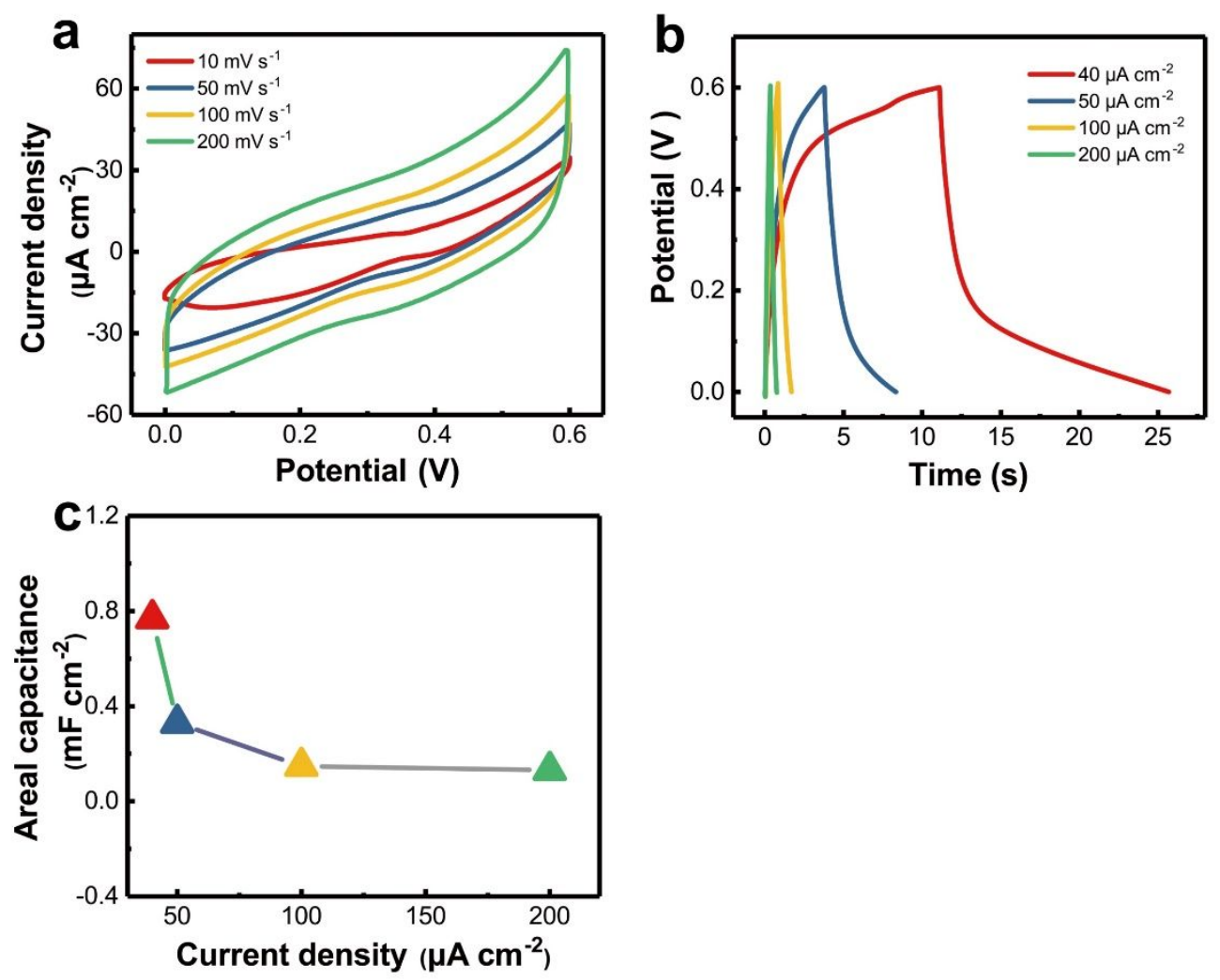

Fig. S6. Electrochemical performance of CuSe based all-solid-state MSC. a) CV curves,

b) GCD curves, e) areal capacitances of pure CuSe-based all-solid-state MSC.
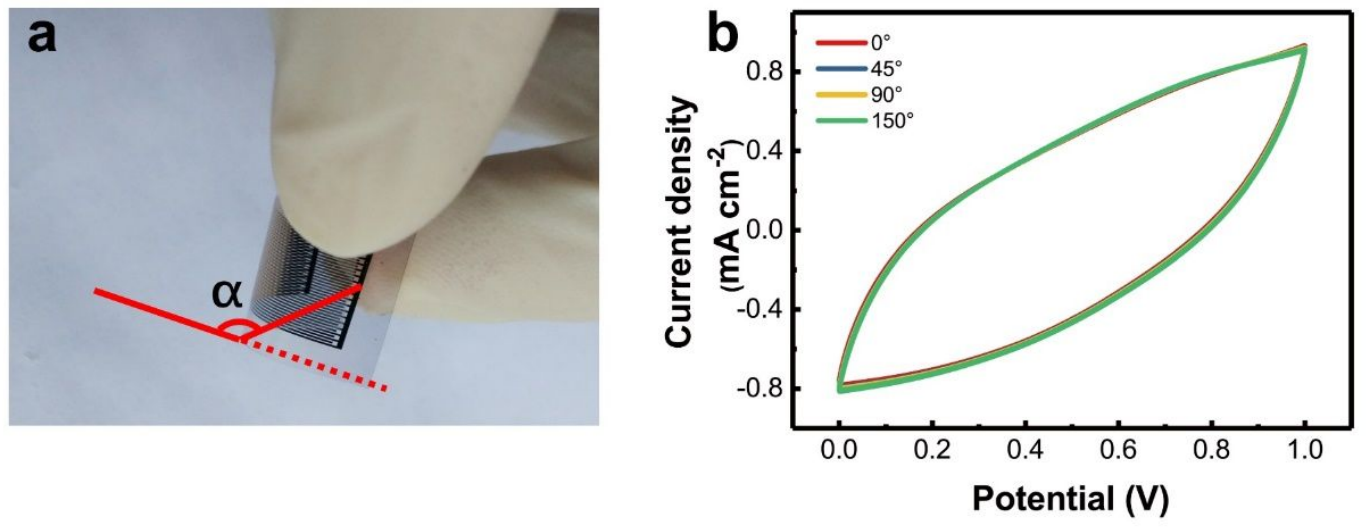

Fig. S7. (a) Photograph of MSC under bending state. (b) CV curves at $100 \mathrm{mV} \mathrm{s}^{-1}$ under different bending angles. 


\section{References :}

1. L. Li, J. Gong, C. Liu, Y. Tian and J. Bao, ACS Omega, 2017, 2, 1089-1096.

2. T.-C. Liu, Y. Hu and W.-B. Chang, Mater. Sci. Eng. B, 2014, 180, 33-37.

3. M. Yang, Z. Shen, X. Liu and W. Wang, J. Electron. Mater., 2016, 45, 19741981.

4. K. Ramesh, B. Bharathi, S. Thanikaikarasan, T. Mahalingam and P. J. Sebastian, J. New Mat. Electrochem. Syst., 2013, 16, 127-132.

5. G. B. Sakr, I. S. Yahia, M. Fadel, S. S. Fouad and N. Romčević, J. Alloys Compd., 2010, 507, 557-562.

6. O. Ramdani, J. F. Guillemoles, D. Lincot, P. P. Grand, E. Chassaing, O. Kerrec and E. Rzepka, Thin Solid Films, 2007, 515, 5909-5912.

7. M. Trchová, Z. Morávková, M. Bláha and J. Stejskal, Electrochim. Acta, 2014, 122, 28-38.

8. A. Shakoor and T. Z. Rizvi, J. Raman Spectrosc., 2010, 41, 237-240.

9. A. A. Rakić, M. Vukomanović, S. Trifunović, J. Travas-Sejdic, O. J. Chaudhary, J. Horský and G. Ćirić-Marjanović, Synth. Met., 2015, 209, 279-296.

10. T. Liu, L. Finn, M. Yu, H. Wang, T. Zhai, X. Lu, Y. Tong and Y. Li, Nano Lett., 2014, 14, 2522-2527.

11. W. Wang, Y. Fan, C. Chen, L. Zhang, Q. Yong and M. Knez, Adv. Mater. Interfaces, 2017, 4, 1600806.

12. N. Jabeen, Q. Xia, M. Yang and H. Xia, ACS Appl. Mater. Interfaces, 2016, 8, 6093-6100.

13. R. Mažeikienè, G. Niaura and A. Malinauskas, Polym. Degrad. Stab., 2008, 93, 1742-1746.

14. X. Tian, X. Bei, X. Xu, X. Lin, Z. Liu, Z. Wang and M. Yan, Nano Res., 2016, 9, 1012-1021. 